\title{
JULES VERNE Y LA CIENCIA EN LA PRENSA ESPAÑOLA DEL SIGLO XIX
}

\section{JULES VERNE AND SCIENCE IN NINETEENTH-CENTURY SPANISH PRESS}

\author{
María-Pilar TRESACO BELÍ́O \\ Universidad de Zaragoza \\ ptresaco@unizar.es
}

Resumen: En el siglo XIX, Jules Verne, desde la publicación del primer Viaje Extraordinario, fue un novelista con mucha repercusión mediática en la prensa española. Cualquier motivo era importante e interesante para incluir una información en los periódicos.

A través de una serie de noticias siempre relacionadas con Verne y sus novelas, en este artículo me propongo presentar cómo la prensa española presentó su perfil y la forma en que los lectores tuvieron acceso, por medio de los periódicos y revistas, a la figura de Verne y la visión que de él se trasmitió.

Abstract: In the nineteenth century, after publishing his first Extraordinay Journey, Jules Verne became widely popular as a novelist in the Spanish press. No matter whether the contemporary news on Verne was truly important or of significant interest to the readers, any information about him was invariably considered relevant and turned into newspapers headlines. 
By focusing on a series of news exclusively related to Verne's career as a writer as well as to his own novels, in this paper I intend to discuss how Verne's profile was defined at that time by the Spanish press and the specific ways in which Verne's public image and popularity were dealt with.

Palabras clave: Jules Verne. Ciencia. Prensa española. Siglo XIX.

Key words: Jules Verne. Science. Spanish Press. Nineteenth Century.

\section{INTRODUCCIÓN}

Al recorrer la vida y por consiguiente la obra de Jules Verne nos encontramos, desde el inicio de los Viajes extraordinarios, con una característica que le acompañará hasta nuestros días: es un autor con etiqueta, siempre se le añade un atributo, se le define como novelista de aventuras, geógrafo, fantasioso, para jóvenes, visionario, de ciencia-ficción, pero sobre todo se le ha catalogado, siempre, de escritor científico como comenta Olivier Dumas (1988: 85): «Malgré une œuvre où dominent les récits sans éléments scientifiques, le public ne retiendra que les ouvrages qui en contiennent, bien qu'ils ne soient qu'une dizaine sur une soixantaine de romans parus». El mismo Jules Verne no se otorgaba ese calificativo y aclaraba, en febrero de 1895, cuando Mari A. Belloc lo entrevistaba para The Strand Magazine (Compère y Margot, 1998: 102) ${ }^{1}$ que «Bueno no pretendo en absoluto ser científico, pero me considero afortunado por haber nacido en una época de notables descubrimientos y puede que aún más maravillosos inventos». Piero Gondolo della Riva (2013: 163) se pregunta «[...] pourquoi la plupart des auteurs d'articles ou d'études sur Jules Verne lui attribuent-ils systématiquement l'étiquette d'inventeur ou de père de la science-fiction, de visionnaire, ignorant tous les aspects littéraires, géographiques, psychologiques de l'œuvre de celui qui mérite d'être considéré comme écrivain tout court?»

Pero ¿cuál era la visión que de Verne tenían sus contemporáneos españoles? En este trabajo queremos presentar esa figura del novelista a través de las informaciones y artículos recogidos en los periódicos españoles de la época. El propio Verne subrayaba, en una entrevista publicada el 13 de julio de 1902 por The Pittsburgh Gazette, bajo el título de «Jules Verne says the Novel Will Soon Be Dead», que «Ce sont les journaux que le monde conservera comme archives historiques» (Compère y Margot, 1998: 177). En ellos,

1 Publicada y traducida en El País semanal del 21 de junio de 1998. 
en los periódicos, nos hemos basado para recopilar la información. En algunos casos nos servimos de la correspondencia de Jules Verne para matizar alguna afirmación.

Hemos delimitado el periodo temporal al comprendido entre la publicación de la primera novela Cinco semanas en globo en 1867 y la muerte del autor acaecida en marzo de 1905. El corpus lo constituyen 111 periódicos y revistas $^{2}$, buscando al elegirlos una representación tanto del lugar de publicación como de sus tendencias ideológicas y temáticas. Para la consulta hemos utilizado las hemerotecas digitales de la Biblioteca Nacional, de la Prensa Histórica y de La Vanguardia. El número de reseñas catalogadas es enorme, pero, en este trabajo, únicamente hemos manejado 519. Esta reducción del corpus viene dada por considerar que no debíamos tener en cuenta los anuncios de las obras, como el insertado en esta sección de La Correspondencia de España el 12 de enero de 1868, ya que solo reflejaban la visión comercial del editor:

\section{FIGURA 1}

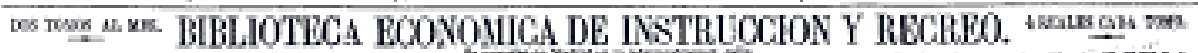

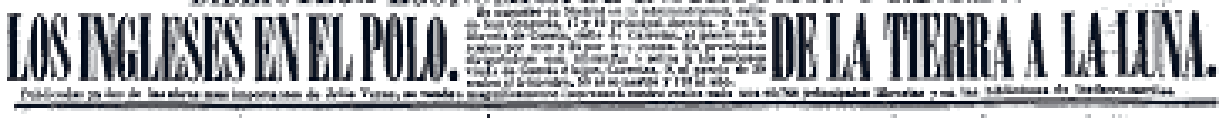

Tampoco hemos analizado la denominada publicidad encubierta, es decir, aquellas noticias cuya finalidad era dar a conocer una novela haciendo un comentario sobre ella y que comenzaron con la publicación de Cinco semanas en globo (La Correspondencia de España: enero de 1867). Siempre se destaca el alto valor de difusión de la ciencia como el publicado por El Constitucional el 12 de enero de 1872 e insertado dentro del apartado de Gacetillas y que resalta el éxito del autor:

Nueva obra de Julio Verne.—Los conocidos editores Sres. Medina y Navarro acaban de publicar en la Biblioteca de Instrucción y Recreo la última y notabilísima obra del eminente escritor francés Julio Verne titulada Una ciudad flotante. Esta obra ha obtenido en los ocho primeros días de la publicación mayor éxito si cabe que las anteriores.

\footnotetext{
2 Ver Anexo I.
} 
No citamos las innumerables veces en que se habla de las adaptaciones de obras al teatro ni la propaganda, críticas y crónicas que ello genera.

Hemos desechado igualmente todas aquellas alusiones que puedan englobarse dentro del apartado de ingeniosidades, chistes y similares como el ejemplo incluido en Madrid cómico del 21 de enero de 1893:

\section{FIGURA 2}

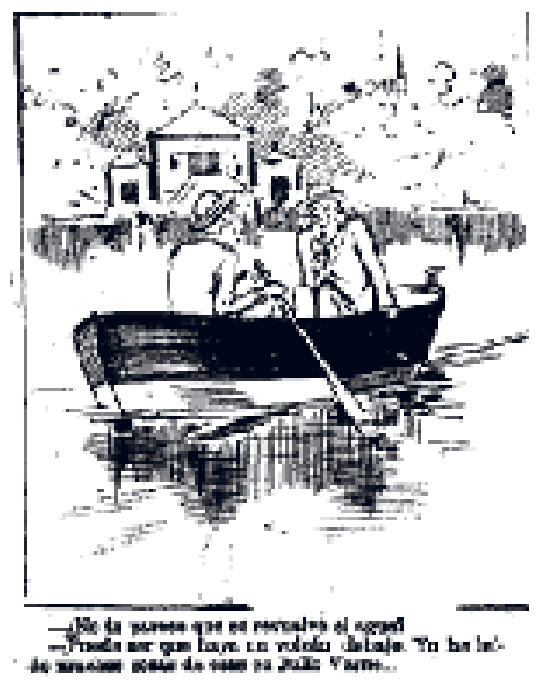

Finalmente, hemos dejado también fuera de este corpus las noticias relativas a la vida particular del autor como sus viajes o el atentado sufrido, hecho recogido por todos los medios de la época, y que en La Vanguardia del 12 de marzo de 1886 se puntualizaba, dentro del apartado Telegramas, de la siguiente forma:

Madrid, 11, á las 3'25 tarde.- Un sobrino de Julio Verne, que habita con él en Amiens y que sufre accesos de locura, disparó al ilustre novelista un revolver, hiriéndole en el pié izquierdo. M. Verne desarmó al agresor. La herida presenta aspecto grave por no haberse podido extraer la bala.

Noticias, a veces acompañadas de grandes errores como la recogida en El Isleño, el 20 de diciembre de 1889, donde se lee «Porque Julio Verne nació en 1822, y tiene, por lo tanto, setenta y cuatro años». Nació en 1828 y si hacemos las cuentas vemos que el resultado no es el correcto. 
Al excluir todas estas variables lo que queremos presentar es la percepción que se tenía de Jules Verne en la prensa a través de aquellas noticias que lo describían como novelista, mostrándolo como referente o garante de un hecho importante o de un acontecimiento relevante. Comentaremos cómo las novelas de la Ciencia, nombre adoptado por Michel Clamen (2005), son una fuente casi inagotable para los periodistas y articulistas del siglo XIX.

Este estudio lo hemos dividido en tres grandes apartados. En el primero, ¿Novelista de la ciencia?, explicamos la percepción que se tenía de Jules Verne con relación a la ciencia. En el segundo, Repercusión de las novelas vernianas, veremos cómo sus novelas más populares eran citadas y servían de comparación o de modelo para cuestiones muy variadas. Finalmente en el tercero, 1905. La última visión, expondremos la consideración, que tras su muerte, se reflejó en la prensa y en todos los casos veremos la conexión existente con la ciencia.

\section{2. ¿NOVELISTA DE LA CIENCIA?}

La figura de Julio Verne surge en las noticias de los periódicos por motivos muy diversos y con apreciaciones muy contrarias. En este apartado hemos recogido las relacionadas con la ciencia y observamos que no había unanimidad en cuanto a la definición o al reconocimiento del concepto de ciencia en Verne. La selección de ejemplos abarca diferentes años y periódicos con el fin de dar una visión lo más amplia posible.

Una de las variantes que se repite es la comparación que se establece entre nuestro novelista y otros autores. El 22 de agosto de 1868, en La Correspondencia de España, dentro de las Gacetillas, al hablar de la última novela del capitán Mayne-Reid utilizan a Verne para alabarla por «sus curiosísimos resúmenes de investigaciones científicas» ya que las obras del primero «son del mismo género de las Julio Verne».

El Porvenir de León (25 de agosto de 1886), en De cómo debe estudiarse la lengua patria, afirma que «Buffon, Flacmarion y Julio Verne, y como ellos otros esclarecidos talentos, escriben sobre ciencias naturales, astronómicas y matemáticas, y lo hacen con galanura de frase y discretísima fantasía de concepto». Años antes, en La Ilustración Artística (18 de junio de 1882), ya se había escrito que «Buffon ha sido el novelista de la Historia natural como Julio Verne es hoy el de las ciencias físicas». 
Son muchas las ocasiones en que nos encontramos artículos en los que se contrasta a Jules Verne con Wells. Así, en Los lunes de El Imparcial (24 de marzo de 1902), R. Fernández Bermúdez en su artículo Los novelistas populares ingleses compara a estos dos autores diciendo que no «existe la menor semejanza» y recoge la idea de que «la ciencia de Julio Verne es la ciencia de mañana ó de pasado mañana», mientras que la de Wells «pertenece á un día más lejano».

No siempre son alabanzas: Ricardo Oyuelos y Pérez, en la Revista del Ateneo Escolar de Guadalajara (5 de marzo de 1883), en Algo sobre nuestra Patria, comenta que «Del mismo modo preferimos trabajos extraños, científicos y artísticos, á los propios y leemos con más placer una novela entera del jocoso Paul de Koch, ó del idealista Julio Verne, que una sola página del clásico y nunca bien enaltecido Cervantes».

Comparación más favorable a Verne es la de Fr. Graciano Martínez, el 15 de octubre de 1904. En el artículo Uso y abuso de la libertad de España y América critica el concepto de novela científica defendida por Zola y sus discípulos y, al compararlos con Julio Verne, no los considera dignos de ningún reconocimiento: «Si hubiesen escrito á la manera de Julio Verne, [...] en libros enderezados á vulgarizar los progresos científicos, todavía se les podría perdonar la pretensión de querer que sus nombres fuesen registrados en la historia de la ciencia».

Son muy destacables las alusiones a la importancia de la presencia de Verne en las bibliotecas, focos de la cultura y depositarias de la ciencia. El 6 de febrero de 1902 en la revista Alrededor del Mundo, en un artículo titulado En la Biblioteca Nacional. Lo que se lee, Roberto de Palacio afirma que «Allí se lee de todo; es decir, casi todo: predomina Julio Verne, desfigurado muchas veces en las papeletas, y así es Verne, como Werne y hasta Berne, poca literatura clásica». En el Discurso pronunciado por el Ministro de Instrucción pública, Excmo. Sr. D. Gabino Bugallal, en la apertura del curso académico de la Universidad de Santiago, publicado por La Escuela Moderna en octubre de 1903, se expone que «Los soldados desatienden las que tratan del arte militar. [...] Todavía nos faltan muchas obras susceptibles de interesar á los soldados, y veríamos con placer figurar en nuestras estanterías las obras de Erckmann-Chatrian, de Julio Verne, de Victor Hugo, etc.».

Centrándonos en los numerosos casos en que se exalta la figura de Verne en relación con la ciencia, observamos que se mencionan diferentes aspectos. Se reconoce su lado instructivo, en los Cabos sueltos de Gil Blas (27 de 
enero de 1868) se dice que «Julio Verne [...] ha conseguido, poner la ciencia en forma de novela, llevando a las inteligencias ocultas el deseo de instruirse al revés de lo que pasa con otras novelas». Tres días más tarde en $L a$ moda elegante leemos que «Son obras que reúnen en alto grado las condiciones que dejamos consignadas como esenciales de la biblioteca: instruir deleitando». En marzo de 1870, en la introducción que sirve de presentación de la revista Los Niños. Revista de Educación y Recreo (nombre copiado de la revista de Hetzel Magasín d'Éducation et Récréation), nos cuentan cómo debe ser la ciencia: «la ciencia tan sencilla, tan encantadora, tan fácil, la amenísima é instructiva de Julio Verne». Mucho más elocuente es el artículo Julio Verne publicado por La Vanguardia (19 de marzo de 1887) y recogido el 26 por el Semanario de Palamós y donde se considera que:

Sus libros, verdaderas obras didascálicas difunden entre el vulgo los áridos estudios de la ciencia, y cuantos hombres hay, que sin necesidad de visitar las aulas poseen muy lúcida instrucción científica que muchos envidian á pesar de sus títulos é infundíos científicos. Entre aquellos debemos contar à Julio Verne. [...] Su genio ha dotado á Francia de un nuevo género de literatura de la cual, hasta ahora, él solo es maestro.

Esta misma idea ya había sido expresada anteriormente por M.R.R., en sus Bosquejos literarios de El Demócrata (16 de diciembre de 1886), al decir que «Julio Verne tiene mucha culpa en que pudiéramos llamar literatura científico-popular [...] Solo él ha sabido probar que todo se puede hacer y decir, diciéndolo y haciéndolo bien». Se constata que, en todos los casos, se asocia la obra de Verne con la ciencia y su papel de divulgación.

José Barbany aúna la figura de Verne con la ciencia y lo explica perfectamente, el 9 de junio de 1888 en La Ilustración Ibérica (Semanario científico, literario y artístico), cuando dedica una página a hablar de Verne:

Julio Verne es un genio excepcional; es un fenómeno de la literatura reinante; es el profeta del siglo XIX; la lumbrera de la edad presente, de esta edad llamémosla eléctrica, tanto por la rapidez de sus ideas como por el vértigo de su desarrollo.

Y la finaliza expresando que:

Julio Verne sintetiza en sus obras los planes de un progreso en ciernes, valiéndose de un especialísimo modo de exponer ideales modelo labrados 
por la ciencia familiarizada con la fábula, dotándola de atractivos irresistibles que llaman á su seno los desarrollos de un porvenir no lejano.

Imagen igualmente defendida por Emilio Poveda García en El Alicantino (4 de febrero de 1890), en la sección Variedades, que tras preguntarse «¿Qué hubiera dicho Ovidio [...] de esta otra metamorfosis de la ciencia moderna?», asegura que aunque hay autores que intentan describir lo que sucederá «es preciso saber hacer la novela científica, si es que existe, y no todos reúnen las condiciones de Julio Verne».

En el espíritu del novelista todas las ciencias, desde la geografía a la astronomía, buscan presentar y describir el mundo. A partir de 1863, la obra verniana se orienta hacia ese discurso técnico. El mismo autor en una entrevista concedida en 1902 (Compère y Margot, 1998: 194) al hablar de la ciencia afirma que:

[J]e lui ai rendu un grand service. Cela a toujours été mon intention première de transmettre des informations sous la forme la plus attrayante, et je suis convaincu que des centaines de milliers de gens se sont mis à aimer les investigations scientifiques en lisant Jules Verne.

Años antes, en la prensa española, se le otorgaba ese mismo mérito: el de divulgador de todas las materias que constituyen la ciencia:

Recordaremos, mejor dicho, presentaremos á nuestros lectores algunas novelas de las que ahora escribe Julio Verne, donde las ciencias naturales, la física, la química, la astronomía y hasta la balística, hallan un lugar y llegan á constituir parte integrante de la fábula novelesca ideada por el autor (Revista de España, julio de 1871).

En historia, en geografía, en astronomía, en viages ${ }^{3}$ en física, en quími$c a$, en artes, en industria, puede la multitud, por medio de esos pequeños libros, hacer acopio de conocimientos, [...] en la senda que tan amena y llana han sabido abrirles Julio Verne, Papillon (Revista de Andalucía: 1874).

Relacionando la ciencia y la poesía encontramos en la última Revista Contemporánea de 1900, firmado por Mariano Arramburo Machado, un largo artículo titulado El ideal artístico donde enuncia «que cuando el artis-

3 Grafía original. 
ta no se preocupa sino de la objetividad, de lo que ve y no de cómo lo ve, la inspiración huye de su cerebro, y la obra producida, más que al arte, corresponde á la ciencia».Por ello considera que Verne puede ser «un gran físico y un gran matemático pero nunca un poeta» y por lo tanto en sus obras habrá «mucha ciencia novelesca» pero no «poesía».

Casi todos concuerdan en el gran conocimiento científico que poseía Verne de estos temas y no como otros que se atreven a escribir sin tener la base necesaria:

Algunos novelistas han hecho conatos de querer aclimatar la novela científica de Julio Verne en nuestro país, conatos sin resultado [...] porque los novelistas que han intentado esto [...] se encuentran absolutamente desprovistos del caudal de conocimientos científicos (El Globo, 11 de febrero de 1877).

Y este conocimiento le hace acreedor de ser citado por la Revista Espiritista (periódico de estudios psicológicos), en noviembre de 1871, como garante de la definición de Júpiter junto con los Espíritus: «No hemos citado esta definición del novelista francés, sino por lo mucho que dice en pocas palabras, y porque está conforme esta apreciación que se deduce de las condiciones físicas y astronómicas de aquel planeta, con lo que han dicho de él algunos Espíritus».

Pero no siempre, como ya hemos comentado anteriormente, Julio Verne será reconocido como un gran novelista científico. Una de las críticas más fuertes es la que apareció en La Nueva Iberia, el 9 de agosto de 1868, en la sección Revista de la semana, donde se lee:

A la casualidad es preciso por lo tanto achacar la boga que ha adquirido entre nosotros cierta clase de libros, que no tienen razón de ser, y cuyo mérito consiste en haber atravesado los Pirineos.

¿Quién no ha comprado ó leído por lo menos las obras de Julio Verne? [...] Es cierto que estos libros, al que sabe poco no le enseñan nada, al que nada sabe rellenan la cabeza de datos aislados, incorrectos y de multitud de errores y falsas apreciaciones.

Y no menos dura es la del 8 de noviembre de 1880, en La América, donde Francisco Cañamaque afirma: «Julio Verne, sobre todo, estimo que es el tipo más acabado del novelista moderno».

El novelista francés no recibe siempre elogios. Así, en la Revista de España, de mayo de 1870, se habla «de los escritores franceses y alemanes 
que se han propuesto convertir la novela en cátedra de ciencias físicas y morales: como Julio Verne que enseña geología en su viaje al centro de la tierra». Por otra parte, en La Ilustración Católica (10 de febrero de 1870), en un artículo sobre la novela, al hablar de Julio Verne se reprueban sus teorías científicas debido «a la misma extravagancia y oscuridad de sus teorías científicas, que la mayor parte de los lectores no entienden». En La Ilustración Catalana (10 de junio de 1881) se reprocha que las obras científicas que tan de moda ha puesto Jules Verne «fant en certes cassos més mal que bé».

A veces, cuesta decidir si lo que leemos es una alabanza o una crítica pero suponemos que, en este caso, se trata más de lo segundo que de lo primero. A la superficialidad de los libros se le suma el bajo nivel del lector, pero por otra parte se destaca su función popularizadora:

Para los que no admiten la enseñanza en la literatura, las obras de Julio Verne son heréticas y abominables; mas para los que aprecian en lo que valen los esfuerzos que tienen como objeto popularizar las ciencias, Verne y los demás escritores que siguen sus huellas son dignos de aprecio y consideración. Algún dato falso, alguna hipótesis absurda se mezclan en sus libros; pero todos ellos contienen enseñanza, que, si bien es superficial, presta un verdadero servicio á las personas totalmente ignorantes (El Globo, 19 de agosto de 1875).

Inciden en esta misma idea El Correo Militar y La Nueva Lucha (1 y 14 de junio de 1887), cuando, con relación a una noticia aparecida en el Times de Nueva York, se dice que «El comunicante, más que en Laplace y Torrice1li, debe haber bebido sus ideas de física en Julio Verne».

Al concepto de ciencia se añade una nueva apreciación con respecto a la obra verniana. Se desarrolla especialmente a partir de mediados de los 80 , se relaciona siempre con algún invento o hecho y se repite incesantemente. Se inicia empleando el concepto de soñar para pasar posteriormente al de fantasear. La ciencia se mezcla con la fantasía. El propio Verne, en una entrevista con Charles Dawbarn en 1904 (Compère y Margot, 1998: 203), explica que $\ll$ Je ne fais que me servir de mon imagination et de mes capacités littéraires pour augmenter à partir de ce qui est possible sur ce qui peut être possible demain». Por consiguiente, no es de extrañar que, en periódicos y revistas destinados a públicos muy diferentes, se sucedan una serie de noticias usando casi la misma formula de comparación:

Estos datos no son sueños fantásticos ni narraciones de Julio Verne (La Dinastía, 1887). 
[P]arece algo así como un sueño, una novela de Julio Verne (Revista Ilustrada de Banca, Ferrocarriles, Industria y Seguros, 1900).

[S]oñada por los novelistas fantaseadores al estilo de Julio Verne (La Época, 1892).

Los americanos son una especialidad en esto de fantasear á lo Julio Verne (La Correspondencia de España, 1892).

[N]o han existido sino en la fantástica imaginación de un croniqueur de excepcionales condiciones para el género científico-fantástico que tan maravillosamente cultiva Julio Verne (Revista de Navegación y Comercio, 1896).

[D]ignos de las semifantásticas novelas casi científicas de Julio Verne (La Correspondencia Militar, 1898).

¿[Q]uién sabe si llegaremos á la casa-automóvil fantaseada por Julio Verne! (La Energía Eléctrica, 1902).

\section{REPERCUSIÓN DE LAS NOVELAS VERNIANAS}

Nos hemos referido a la percepción y difusión que de la figura de Verne se transmitía en la prensa española, pero sin hacer referencia concreta a ninguna de las novelas de los Viajes Extraordinarios. Sin embargo, estas obras fueron muy citadas y utilizadas por los periódicos del siglo XIX y generalmente para dar valor e importancia a lo que se estaba comentando.

Dos son las novelas que sobresalen y por motivos muy diferentes: Veinte mil leguas de viaje submarino (1869/70) y La vuelta al mundo en ochenta días (1872). Sin embargo queremos exponer, primeramente, la divulgación que tuvieron las noticias relacionadas con otras cuatro novelas.

\subsection{Viaje al centro de la Tierra (1864)}

«Un geógrafo inglés, R. Picknell, [...] un proyecto tan temerario como original. Se trata de llevar á la práctica los fantásticos cálculos de Julio Verne, verificando un viaje al centro de la tierra». Esta noticia recorrió toda la geografía española y así la podemos ver entre mayo y 
septiembre de 1889 en los siguientes periódicos, escogidos por ser representativos de las provincias: La Crónica de Huesca, El Alicantino, La Palma de Cádiz, El Diario de Orihuela, El Bien Público y El Liberal de Mahón, El Porvenir de León y La Semana Católica de Salamanca.

\subsection{Los hijos del capitán Grant (1866/67)}

En este caso la noticia hace referencia a la acción sedativa del aceite sobre las olas agitadas. Aparece ya recogida el 16 de enero de 1883, en El Globo, en el apartado de La ciencia al día, donde se equipara la ciencia de Verne a la de los grandes científicos:

Es este un fenómeno que viene estudiándose desde hace mucho tiempo; lo observaron muchos sabios, entre los cuales se encuentran Franklin, Van Lelvelt, el abate Manú, Van Beck, Lecuw y otros. El mismo Julio Verne ha hecho intervenir el aceite con carácter maravilloso en Los hijos del capitán Grant para salvar al Duncan de una horrorosa tormenta.

Años después, el 5 de junio de 1897, La Unión Católica, al hablar del aceite y las tempestades del mar, reconoce que «Julio Verne, en su novela, Los hijos del capitán Grant, fue el primero que indicó el uso del aceite para calmar las tempestades marítimas».

\subsection{De la Tierra a la Luna (1865) y Viaje alrededor de la Luna (1869)}

Desde 1873 a 1904 el viaje a la Luna descrito por Verne sirve de referente para todo aquello que tenga que ver con los telescopios, los eclipses, los imposibles intentos de viaje o cualquier invento relacionado con este satélite. Estas reseñas se publicaron no solo en diarios sino que también aparecieron en publicaciones especializadas, como Crónica Científica, El Progreso Agrícola y Pecuario, La Correspondencia Militar, Madrid Científico o El Mundo Naval Ilustrado.

\subsection{Un billete de lotería (1886)}

En la trama de esta novela Verne explica cómo se realiza un sorteo de lotería. En 1887, un año después de su traducción y publicación, entre no- 
viembre y diciembre, en la prensa se promueve una gran polémica originada por el Ministro de Hacienda y su reforma del sorteo:

Conocíamos al Sr. Puigcerver demócrata, le conocíamos ministro de Hacienda, le conocíamos republicano, le conocemos abogado; pero jamás pudimos creerle traductor de novelas. Y hé aquí que, cuando menos lo esperábamos, el demócrata ministro lee una novela de Julio Verne, le gusta, la traduce, y en vez de servirse de cualquier periódico, de El Mundo su amigo, por ejemplo, para folletín, lo lleva a la Gaceta y establece el sorteo por irradiación (La Monarquía, 6 de noviembre de 1886).

Esta controversia se extendió por otros periódicos como La Iberia, La Ilustración Española y Americana, La Vanguardia, El Liberal o La Época.

Se zanjó en 1900, como se advierte en La Ilustración Española y Americana, «á Julio Verne sólo se le ocurrió que se sacaran las bolas unas niñas, todo esto está demostrado con fechas y la reforma del señor Puigcerver fue combatida por los que siempre se oponen á todas las mejoras».

\subsection{La vuelta al mundo en 80 días (1872)}

Esta novela sirvió a lo largo de muchos años como punto de comparación para cualquier viaje que tuviera como finalidad la vuelta al mundo.

El 17 de mayo de 1873 se anunciaba la publicación de La vuelta al mundo en 80 días en La Discusión, donde se dice: «El nombre del autor es por sí solo una eficaz recomendación; amena, instructiva, conteniendo gran fondo de doctrina científica». Cuando algunos intrépidos viajeros, como MM. Yaret y Palmer, la familia Ismay y Mme Barrow o Mr. Georges-Francis Train, deciden emular a Phileas Fogg, las comparaciones se multiplican.

Pero sin ninguna duda, el viaje más seguido fue el realizado por Nellie Bly, tanto por el hecho de ser una señorita americana, como por reducir el número de días. Los comentarios que origina su viaje son muy numerosos, así como el hecho de ser recibida por Jules Verne en su casa de Amiens (Compère y Margot, 1998: 56-58). Cuando se anuncia en toda la prensa nacional su posible hazaña, se refleja perfectamente la situación de la mujer frente al hombre, ya que para finalizar la noticia los articulistas añaden que: «Tiene por objeto la atrevida señora demostrar que una señora no hablando más que el inglés puede atravesar el mundo como guste y sin amparo de nadie. Muy bien. Puede suceder que consiga su objeto; pero, en un viaje tan 
apresurado, tendrá muchísimo cansancio y ventaja ninguna». La noticia se extendió entre el 28 de noviembre y el 17 de diciembre de 1889 por toda la geografía española. Se recoge, por ejemplo, en La Provincia de Gerona, La Crónica y La Correspondencia Española de Madrid, La Crónica Meridional de Almería, El Isleño de Palma de Mallorca o La Crónica de Huesca.

Se recuerda incluso en la Revista de Navegación y Comercio, 20 años después de la aparición de la novela (15 de marzo de 1893), al analizar las derrotas de ida y vuelta entre Inglaterra y Nueva York se concreta que el viaje alrededor del mundo «es más sencillo y ni tan siquiera se tardan los ochenta días de Julio Verne».

No solo se nombró La vuelta al mundo en 80 días para relatar otros viajes, también se utilizó como referencia para anunciar una nueva línea ferroviaria: «El Transcontinetal Pacific Memphis es la inmensa línea férrea que va desde Nueva York á San Francisco. Para demostrar su importancia, vamos á copiar la descripción que de ella hace la curiosa obra de Julio Verne, titulada La vuelta al mundo en 80 días» (Diario Oficial de Avisos, 10 de marzo de 1873). Sucede lo mismo con el ferrocarril «trasasiático» (El Imparcial, 9 de abril de 1877) o el ferrocarril Transiberiano (Boletín de la Sociedad Geográfica de Madrid, $1{ }^{\mathrm{er}}{ }^{\mathrm{r}}$ semestre de 1890 y El Heraldo de Madrid, 27 de noviembre de 1900).

Se recurre a la novela verniana para explicar diferentes hechos, denominados científicos, como los husos horarios que recoge la Gaceta de Instrucción Pública (16 de junio de 1900) en un artículo titulado ¿Dónde empieza el día? Igualmente lo podemos encontrar para averiguar por qué y cómo las cartas o las noticias periodísticas podrían leerse antes (Revista de Geografía comercial, noviembre y diciembre de 1894 y La Revista Blanca, 15 de noviembre de 1904).

\subsection{Veinte mil leguas de viaje submarino (1869/70)}

En el verano de 1868, Jules Verne en cartas dirigidas a su padre y a su editor Hetzel comenta que «J'espère que toutes ces invraisemblances parâ̂tront vraisemblances» (Dumas, 1988: 445; Dumas, Dehs y Gondolo della Riva, 1999: 85). Se está refiriendo al argumento de la novela que está escribiendo, Veinte mil leguas de viaje submarino.

El Nautilus verniano toma prestadas características de otros aparatos anteriores, pero Verne las personaliza con unas singularidades que lo con- 
vierten en inédito, premonitorio a la vez que irreal. Todos los submarinos que surgen después harán referencia a él: se convirtió en un símbolo, en el icono de todos ellos. Otra característica de estas reseñas es cómo se destacan las especificaciones aportadas por Verne.

Como muestra de este hecho expondremos un rápido recorrido por los diferentes submarinos fabricados en ese periodo y que sintetizamos en los ejemplos siguientes:

Julio Verne puede estar satisfecho: sus invenciones se llevan á la práctica por sabios de la fuerza de Nordenfield [...] He aquí la descripción de un verdadero Nautilus con el cual se han hecho ya algunas experiencias (La Ilustración Católica, 5 de abril de 1886).

El primer barco movido por la electricidad. [...] El otro descubrimiento se refiere al buque submarino soñado por Julio Verne en su popular novela [...] con la curiosa particularidad de que el buque ha sido construido siguiendo todas las indicaciones apuntadas en su famosa novela por el ingenioso escritor, al describir el Nautilus del capitán Nemo. [H] a sido bautizado con el nombre de Peacemaker (La Época, 24 de septiembre; Bandera Social, 18 de noviembre de 1886).

El submarino de Gresham. [...] El fantástico Nautilus, creado por la maravillosa imaginación de Julio Verne, sigue sugestionando á los inventores de construcciones marítimas. [...] verificó el Goubet sus últimos ensayos favorables, [...] la aparición de un nuevo barco de condiciones tan excepcionales [...] la nave soñada por el autor de Veinte mil leguas de viaje submarino, tendrá dentro de poco realización completa (Revista de Navegación y Comercio, 30 de mayo de 1896).

Apuntes sobre los grandes inventos del mundo. [...] En estos momentos se hacen pruebas parciales del buque submarino proyectado por D. Isaac Peral. $[P]$ odrá recorrer el mar como dominio propio y explorar sus fondos y descubrir sus riquezas; todo lo que la imaginación de J. Verne ha creado en su Nautilus, será un hecho con el submarino Nautilus (El Día, 25 de enero de 1900).

Los progresos de la navegación submarina.

Gracias á los progresos de la ciencia, el problema de la navegación submarina está muy próximo á ser resuelto de un modo satisfactorio, y por lo tanto, el que pueda ser una realidad aquel famoso viaje de «veinte mil leguas de viaje submarino» en que el originalísimo Julio Verne evocó los grandiosos espectáculos y dramáticas peripecias de un viaje de tal género (Mar y Tierra, 26 de mayo de 1900). 
Queremos terminar este breve periplo por los submarinos inspirados en Verne con un pequeño poema publicado en La Propaganda del Burgo de Osma, el 19 de julio, y que dedicado Al insigne Peral dice en su cuarta estrofa:

Con la ciencia, por enseña, del hombre el genio se empeña

$y$ da en tan gigante liza

á Julio Verne que sueña

y á Isaac Peral que realiza.

La presencia de Verne no se limita a los submarinos nombrados, sino que aparece relacionada con los de Ruggero y de Monturiol o con los que se van a construir impulsados por la electricidad.

A Verne y su novela Veinte mil leguas de viaje submarino se le asoció siempre con los avances tecnológicos, es decir con la ciencia.

\section{1905: LA ÚLTIMA VISIÓN}

El 24 de marzo de 1905 Jules Verne muere en Amiens. Sabemos que no era ni matemático, ni astrónomo, ni geógrafo, ni un inventor de máquinas, ni el autor de manuales científicos. Era un incansable lector que como escritor buscaba proporcionar nuevos conocimientos a sus seguidores. El propio autor, al hablar de ello, en una entrevista concedida en febrero de 1905 al Transcript de Boston (Compère y Margot, 1998: 221), decía:

Ces cö̈ncidences sont dues en grande partie au fait qu'en imaginant des merveilles scientifiques, j'ai toujours essayé de rendre les choses aussi simples et vraies que possible. Toute ma vie j'ai pris beaucoup de notes et je me suis abonné à de nombreux journaux, magazines, revues et rapports scientifiques.

Pero la prensa española del XIX no pensaba como el novelista en cuanto a sus méritos. Se recoge, de manera inmediata y extensa, la luctuosa noticia y, como sucedió en vida, al hablar de su muerte también se incluyen algunas invenciones y falsedades. Así Julio Rojo en su crónica comunicaba, junto a 
su gran respeto al insigne narrador, una matización, con respecto a su trabajo, totalmente errónea:

A estas horas habrá ya fallecido [...] Hace unos tres años que había muerto para la producción literaria. [...] Yo debo al insigne narrador las primeras grandes emociones de los hechos científicos. [...] Despertaste en mí el ansía de saber (El Castellano, 24 de marzo de 1905).

Jules Verne siguió trabajando, evidentemente a un ritmo mucho más pausado, hasta el último momento. Volker Dehs (2005: 168) matiza que:

Se le hace imposible escribir, al menos cuando su mano derecha se ve atacada de calambres y, sin embargo, Jules Verne sigue trabajando en sus Viajes Extraordinarios sin recibir ayuda: hasta el final todos los manuscritos son de su puño y letra, una letra que cada vez se va haciendo más ilegible.

Por otro lado, se reconoce la creación científica del octogenario, que en realidad tenía 76 años al morir:

[V]erdadero creador de la novela científica que ha consagrado su larga existencia, más que octogenaria, á la vulgarización de los adelantos y conocimientos científicos: casi no hay problema alguno en los horizontes de la ciencia que no haya abordado el sabio novelista en sus preciosas novelas (Eco de la Alcarria, 29 de marzo).

Cabe destacar que en todos los casos se subraya el aspecto científico de su obra.

En cuanto a la iconografía, únicamente en unos pocos casos se acompaña la noticia con un retrato del novelista, como la de El Liberal del 25 de marzo de 1905 que anuncia su muerte de una forma escueta pero rotunda. En la crónica que sigue a la imagen, Antonio Zozaya lo defiende al describirlo como un gran investigador:

Lo que no ven ó no quieren ver, los detractores de aquel gran investigador (así como suena) es que en sus obras no todo era candor. Había el reconocimiento, es más, la afirmación explícita de que los estudios experimentales, positivos, debían ser considerados como de capital y primera importancia, ni más ni menos que en Conte ó Littré. 
Si se unifican las ideas que a su muerte se recogen en la prensa de cualquier lugar de España, podemos decir que se centran en reconocer su carácter científico, aunque con diferentes apreciaciones. Alaban sus conocimientos, de todo tipo: «Poseedor de grandes conocimientos, físico y matemático, gran geógrafo, une á estas condiciones la definitiva para el artista, una fantasía poderosísima» (El Imparcial, 22 de marzo). Lo llaman el poeta de la ciencia: «El gran novelista francés fue el poeta de la ciencias: el hombre que encontró el secreto de unir la aridez del álgebra con la amenidad de la narración que interesa y conmueve» (La Correspondencia de España, 24 de marzo). Lo aclaman como gran propagandista de las ciencias «La muerte de Julio Verne es un gran desastre para la cultura. El gran francés había sido y era un gran propagandista de las ciencias» (El Graduador, 24 de marzo).

M. Roso de Luna (El Globo, 30 de marzo) lo ensalza como el soñador científico: «Pasó á mejor vida este delicioso soñador científico, uno de los que más han influido en la educación intelectual de la segunda mitad del siglo XIX».

L. Rodríguez Abarrategui lo define como «El vulgarizador de la ciencia por medio de la novela amenísima é instructiva, ha muerto dejando en el mundo de las letras un vacío difícil de llenar» (El Radical, 26 de marzo). Idea que se refleja en otros periódicos, diciendo que «descripciones geográficas, hábilmente combinadas con un profundo caudal de conocimientos físico-químicos y matemáticos [...] este ingenioso vulgarizador de la ciencia» (El Guadalete, 28 de marzo); «como vulgarizador de conocimientos científicos, tiene el raro mérito de haberlos popularizado realmente con el éxito no superado de sus narraciones» (La Ilustración Española y Americana, 30 de marzo); «Y sus hondos problemas científicos se los dio al vulgo en forma sencilla y encantadora, presentándolos como una dulce amenidad de gabinete» (Vida Galante, 7 de abril). De esta misma opinión es Arturo Masriera al afirmar que:

Nadie, antes ni después de Julio Verne, ha dado a conocer con más espléndida variedad y profusión esta masa cósmica que llamamos mundo; nadie ha deducido para la industria, la navegación, la astronomía y la química, tantas aplicaciones y ha revelado tantas orientaciones nuevas para el desarrollo de las mismas. El talento de difundir vulgarizado, es patrimonio de pocos, y el escritor francés lo ha poseído con perfección rarísima (Correo Ibérico, 7 de abril). 
En numerosos casos se resalta la manera de trasmitir sus increíbles conocimientos científicos:

Con maravillosa inventiva y á veces con proféticas intuiciones no sólo transformaba en verdaderas novelas los descubrimientos de la ciencia, sino que se anticipaba en algunas ocasiones a estos descubrimientos formulando atrevidas hipótesis, sentando principios, paradójicos en apariencia, que luego se convertían en realidades (La Ilustración Artística, 3 de abril).

Por su parte Daniel Bascuñana Charfolé escribe:

Este ilustre francés, de universal y bien merecido renombre, ha sido un escritor cuyas obras, sumamente plácidas y sabiamente razonadas, van dejando por todo el mundo un vivo deseo de investigaciones físico-químicas, geográficas, geológicas, atmosféricas[...] Julio Verne ha preferido descender á las entrañas de la tierra y á los abismos del mar, para que la curiosidad de la mente investigadora tenga á su alcance todo el realismo posible del planeta en que vivimos (El Motín, 25 de marzo).

Muchos lo bautizan como el creador de la novela científica y geográfica: «Con él puede decirse que ha desaparecido el fundador de la novela científica, género que hoy cuenta tantos partidarios» (Por esos Mundos, 1 de abril); «Ha sido el creador del género de la novela científica y geográfica, revelando un genio descriptivo de los más notables y atesorando en sus producciones profundos conocimientos científicos» (El Día y El Globo, 25 de marzo); «creando un género nuevo, la novela científica y geográfica. Su talento de novelador» (La Crónica Meridional, 26 de marzo); «Ha sido el creador del género de la novela científica y geográfica, revelando un genio descriptivo de los más notables y atesorando en sus producciones profundos conocimientos científicos» (La Defensa, 28 de marzo).

Queremos finalizar este recorrido por la visión que a lo largo de su vida se reflejó en la prensa española con la crónica de La Vanguardia, del 26 de marzo, firmada por Juan Buscón y que sirve como síntesis de todo lo expuesto y comentado anteriormente:

[E]l hecho de haber sido durante cuarenta años ese escritor uno de los novelistas más populares, tal vez, el más popular de todos, ha bastado para que algunos críticos pertenecientes al gremio de los gruñones le trataran con marcado desdén, calificándole de poco literario, reprochándole el ser un novelista «bueno para las masas» no para los espíritus refinados, de altos ideales y exquisito gusto. [...] fue el inventor de un nuevo é interesantísimo género lite- 
rario-científico. Y repito «científico» que los sabios juzgarán sin duda pretencioso aplicado á los relatos de tan extraordinaria fantasía de Julio Verne quien por otra parte no tuvo jamás la pretensión de «hacer ciencia»-porque en las páginas de sus amenísimos libros hay un verdadero derroche de conocimientos en diversos ramos de la ciencia humana.

\section{CONCLUSIÓN}

En este estudio efectuado a través de la prensa española del siglo XIX hemos podido comprobar que Jules Verne (en la prensa española siempre es Julio) era una figura que despertaba mucho interés entre sus contemporáneos, de allí las numerosísimas veces que es citado.

Se le consideraba un escritor muy bien informado y con un gran espíritu científico. Se le calificaba de inventor a la par que divulgador de la novela científica. Su figura era mayoritariamente ensalzada y solo en raros casos se la criticaba y en ese caso se le etiquetaba de fantasioso o con una imaginación desbordante.

Se buscaba poder relacionar o añadir el nombre de Verne o de sus novelas a cualquier invento o acontecimiento, ya que suponía un apoyo muy considerable.

Una característica esencial de la presencia de Jules Verne en los periódicos y revistas españolas es el hecho de que no importa ni el lugar de publicación, ni la ideología, ni la temática: en todos los sitios, en cualquier momento y por infinitos motivos, su presencia es requerida y siempre bienvenida.

Podemos resumir todo lo expuesto diciendo que en la prensa española del siglo XIX, Jules Verne era un referente para todo aquello que implicara o supusiera una innovación, una osadía, un invento, una fantasía, un hecho científico y para todo aquello que la gente pudiera o quisiera idear o soñar.

Indudablemente, en la actualidad española del siglo XIX, las palabras Verne y ciencia iban unidas.

\section{REFERENCIAS BIBLIOGRÁFICAS}

CLAMEN, M. (2005). Jules Verne et les sciences. Cent ans après. Paris: Belin. COMPÈRE, D. \& MARGOT, J.-M. (1998). Entretiens avec Jules Verne 1873-1905. Genève: Slatkine. 
DEHS, V. (2005). Jules Verne. Madrid: EDAF.

DUMAS, O. (1988). Jules Verne: Avec la publication de la correspondance inédite de Jules Verne à sa famille. Lyon: La Manufacture.

DUMAS, O.; DEHS, V. y GONDOLO della RIVA, P. (1999). Correspondance inédite de Jules Verne et de Pierre-Jules Hetzel (18631886). Genève: Slatkine [Paris] [diff. H. Champion].

GONDOLO della RIVA, P. (2013). «Jules Verne et le futur». En De Julio Verne a la actualidad: la palabra y la tierra, M. P.Tresaco, J. Vicente y M. L. Cadena (eds.), 155-164. Zaragoza: Prensas de la Universidad de Zaragoza.

SERRES, M. (2003). Jules Verne la science et l'homme contemporain. Conversations avec Jean-Paul Dekiss. Paris: Le Pommier.

Recibido el 30 de junio de 2013.

Aceptado el 19 de septiembre de 2013. 


\section{ANEXO I \\ Relación de los periódicos y revistas consultados}

Se indica (1) el lugar y (2) los años disponibles en las hemerotecas de la Biblioteca Nacional y de la Prensa Histórica.

Especificación del lugar de consulta:

HN: Hemeroteca Nacional. http://hemerotecadigital.bne.es/index.vm

PH: Prensa Histórica. http://prensahistorica.mcu.es/es/consulta/busqueda.cmd *: http://www.lavanguardia.com/hemeroteca/index.html

\begin{tabular}{|l|l|c|c|c|}
\hline & \multicolumn{1}{|c|}{$(1)$} & $(2)$ & $\mathrm{HN}$ & $\mathrm{PH}$ \\
\hline Álbum Salón & Barcelona & $1897-1907$ & $\mathrm{X}$ & \\
\hline Alma Española & Madrid & $1903-1904$ & $\mathrm{X}$ & \\
\hline Almanaque Bailly-Bailliere & Madrid & $1895-1937$ & $\mathrm{X}$ & \\
\hline Alrededor del Mundo & Madrid & $1899-1930$ & $\mathrm{X}$ & \\
\hline Archivo Diplomático y Consular de España & Madrid & $1884-1885$ & $\mathrm{X}$ & \\
\hline Asta Regia & Jerez de la Frontera & $1880-1883$ & $\mathrm{X}$ & \\
\hline $\begin{array}{l}\text { Bandera Social. Semanario Anárquico- } \\
\text { Colectivista }\end{array}$ & Madrid & $1885-1886$ & $\mathrm{X}$ & \\
\hline Barcelona Cómica & Barcelona & $1889-1900$ & $\mathrm{X}$ & \\
\hline $\begin{array}{l}\text { Boletín de la Sociedad Geográfica de } \\
\text { Madrid }\end{array}$ & Madrid & $1876-1900$ & & $\mathrm{X}$ \\
\hline Correo Ibérico: Diario Católico & Tortosa & $1904-1908$ & & $\mathrm{X}$ \\
\hline $\begin{array}{l}\text { Crónica Científica: Revista Internacional } \\
\text { e Ciencias }\end{array}$ & Barcelona & $1880-1891$ & & $\mathrm{X}$ \\
\hline Diario de Tortosa & Tortosa & $1898-1919$ & & $\mathrm{X}$ \\
\hline Diario Oficial de Avisos de Madrid & Madrid & $1847-1917$ & $\mathrm{X}$ & \\
\hline Eco de la Alcarria: Semanario Católico & Guadalajara & $1903-1905$ & & $\mathrm{X}$ \\
\hline El Álbum Ibero Americano & Madrid & $1847-1917$ & $\mathrm{X}$ & \\
\hline El Alicantino: Diario Católico & Alicante & $1888-1894$ & & $\mathrm{X}$ \\
\hline El Bien Público & Mahón & $1873-1939$ & & $\mathrm{X}$ \\
\hline El Castellano & Salamanca & $1904-1915$ & & $\mathrm{X}$ \\
\hline El Constitucional & Alicante & $1871-1887$ & & $\mathrm{X}$ \\
\hline El Correo Militar & Madrid & $1883-1901$ & $\mathrm{X}$ & \\
\hline El Demócrata & Gerona & $1881-1887$ & & $\mathrm{X}$ \\
\hline El Día & Madrid & $1881-1908$ & $\mathrm{X}$ & \\
\hline El Diario de Orihuela & Orihuela & $1886-1891$ & & $\mathrm{X}$ \\
\hline El Globo & Madrid & $1875-1932$ & $\mathrm{X}$ & \\
\hline El Graduador & Alicante & $1876-1913$ & & $\mathrm{X}$ \\
\hline El Guadalete & Jerez de la Frontera & $1883-1918$ & & $\mathrm{X}$ \\
\hline El Heraldo de Madrid & Madrid & $1890-1939$ & $\mathrm{X}$ & \\
\hline El Imparcial & Madrid & $1868-1933$ & $\mathrm{X}$ & \\
\hline & & & & \\
\hline
\end{tabular}




\begin{tabular}{|c|c|c|c|c|}
\hline & (1) & (2) & $\mathrm{HN}$ & $\mathrm{PH}$ \\
\hline El Isleño & Palma de Mallorca & $1857-1898$ & & $\mathrm{X}$ \\
\hline El Liberal & Mahón & $1881-1906$ & $X$ & \\
\hline $\begin{array}{l}\text { El Lloretense: periódico científico, } \\
\text { literario y... }\end{array}$ & Gerona & 1885 & & $\mathrm{X}$ \\
\hline El Magisterio Balear & Palma Mallorca & $1873-1916$ & & $\mathrm{X}$ \\
\hline El Motín & Madrid & $1881-1924$ & $\mathrm{X}$ & \\
\hline El Mundo Cómico & Madrid & $1872-1876$ & $\mathrm{X}$ & \\
\hline El Mundo de los Niños & Madrid & $1887-1891$ & $\mathrm{X}$ & \\
\hline El Mundo Naval Ilustrado & Madrid & $1897-1901$ & $\mathrm{X}$ & \\
\hline El País (El Nuevo País) & Madrid & $1887-1921$ & $\mathrm{X}$ & \\
\hline El Periódico para todos & Madrid & $1872-1882$ & $\mathrm{X}$ & \\
\hline El Porvenir de León & León & $1875-1915$ & & $\mathrm{X}$ \\
\hline El Progreso Agrícola y Pecuario & Madrid & $1899-1936$ & $X$ & \\
\hline El Radical & Almería & $1902-1917$ & & $\mathrm{X}$ \\
\hline El Semanario Murciano & Murcia & $1878-1882$ & $\mathrm{X}$ & \\
\hline El Siglo Futuro & Madrid & $1875-1936$ & $\mathrm{X}$ & \\
\hline España y América & Madrid & $1903-1927$ & $\mathrm{X}$ & \\
\hline Gaceta de Instrucción Pública & Madrid & $1899-1907$ & $\mathrm{X}$ & \\
\hline Gaceta de los Caminos de Hierro & Madrid & $1856-1934$ & $\mathrm{X}$ & \\
\hline Gil Blas & Madrid & 1864-1872 1882 & $X$ & \\
\hline Hojas Selectas & Barcelona & $1902-1921$ & $\mathrm{X}$ & \\
\hline Industria é Invenciones & Barcelona & $1884-1915$ & $\mathrm{X}$ & \\
\hline La Abeja & Barcelona & $1862-1870$ & $\mathrm{X}$ & \\
\hline La América & Madrid & $1857-1886$ & $\mathrm{X}$ & \\
\hline La Correspondencia de España & Madrid & $1860-1925$ & $\mathrm{X}$ & \\
\hline La Correspondencia Militar & Madrid & $1897-1932$ & $\mathrm{X}$ & \\
\hline La Crónica & Huesca & $1885-1892$ & & $\mathrm{X}$ \\
\hline La Crónica de León & León & $1875-1881$ & $\mathrm{X}$ & \\
\hline La Crónica Meridional & Almería & $1874-1936$ & & $\mathrm{X}$ \\
\hline La Defensa & Alcoy & 1904-1911 & & $\mathrm{X}$ \\
\hline La Diana & Madrid & $1883-1884$ & $\mathrm{X}$ & \\
\hline La Dinastía & Barcelona & 1883-1904 & $\mathrm{X}$ & \\
\hline La Discusión & Madrid & $1856-1887$ & $\mathrm{X}$ & \\
\hline La Energía Eléctrica & Madrid & $1899-1933$ & $X$ & \\
\hline La Enseñanza & Madrid & $1865-1868$ & $X$ & \\
\hline La Época & Madrid & $1849-1936$ & $\mathrm{X}$ & \\
\hline La Escuela Moderna & Madrid & $1892-1894$ & $\mathrm{X}$ & \\
\hline La España & Madrid & $1848-18681887$ & $\mathrm{X}$ & \\
\hline La España Moderna & Madrid & $1892-1934$ & $\mathrm{X}$ & \\
\hline La Esperanza & Madrid & $1844-1874$ & $\mathrm{X}$ & \\
\hline La Iberia & Madrid & $1854-1898$ & $X$ & \\
\hline La Ilustración Artística & Barcelona & $1882-1916$ & $\mathrm{X}$ & \\
\hline La Ilustración Catalana & Barcelona & $1880-1892$ & $\mathrm{X}$ & \\
\hline
\end{tabular}




\begin{tabular}{|c|c|c|c|c|}
\hline & (1) & (2) & $\mathrm{HN}$ & $\mathrm{PH}$ \\
\hline La Ilustración Católica de España & Madrid & $1897-1899$ & $\mathrm{X}$ & \\
\hline La Ilustración Española y Americana & Madrid & $1869-1921$ & $\mathrm{X}$ & \\
\hline La Ilustración Ibérica & Barcelona & $1883-1898$ & $\mathrm{X}$ & \\
\hline La Lectura Dominical & Madrid & $1894-1936$ & $\mathrm{X}$ & \\
\hline La Lectura. Revista de Ciencias y de Artes & Madrid & $1901-1920$ & $\mathrm{X}$ & \\
\hline La Lidia & Madrid & $1882-1927$ & $\mathrm{X}$ & \\
\hline La Moda Elegante & Cádiz & $1861-1923$ & $\mathrm{X}$ & \\
\hline La Monarquía & Madrid & $1887-1890$ & $\mathrm{X}$ & \\
\hline La Nación Militar & Madrid & $1899-1912$ & $\mathrm{X}$ & \\
\hline La Nueva Iberia & Madrid & 1868 & $\mathrm{X}$ & \\
\hline La Nueva Lucha & Gerona & $1887-1990$ & & $\mathrm{X}$ \\
\hline La Palma de Cádiz & Cádiz & $1853-1891$ & & $\mathrm{X}$ \\
\hline La Propaganda & Burgo de Osma & $1882-1892$ & & $\mathrm{X}$ \\
\hline La República & Madrid & $1873,1884-1891$ & $\mathrm{X}$ & \\
\hline La Revista Blanca & Madrid & $1900-1936$ & $\mathrm{X}$ & \\
\hline La Semana Católica de Salamanca & Salamanca & $1886-1912$ & & $\mathrm{X}$ \\
\hline La Tarde & Palma de Mallorca & $1903-1912$ & & $\mathrm{X}$ \\
\hline La Unión Católica & Madrid & $1887-1899$ & $\mathrm{X}$ & \\
\hline La Vanguardia* & Barcelona & $1881-$ & & \\
\hline La Voz de Alicante & Alicante & 1904-1909 & & $\mathrm{X}$ \\
\hline Las Dominicales del Libre Pensamiento & Madrid & $1883-1909$ & $\mathrm{X}$ & \\
\hline Los Niños: Revista de Educación y Recreo & Madrid & $1870-1876$ & & $\mathrm{X}$ \\
\hline Madrid Científico & Madrid & $1897-1936$ & $\mathrm{X}$ & \\
\hline Madrid Cómico & Madrid & $1880-1923$ & $\mathrm{X}$ & \\
\hline Mar y Tierra & Barcelona & $1900-1901$ & $\mathrm{X}$ & \\
\hline Nuestro Tiempo & Madrid & 1901-1926 & $\mathrm{X}$ & \\
\hline Nuevo Mundo & Madrid & $1895-1933$ & $\mathrm{X}$ & \\
\hline Por Esos Mundos & Madrid & $1900-1926$ & $\mathrm{X}$ & \\
\hline Revista Contemporánea & Madrid & $1875-1907$ & $\mathrm{X}$ & \\
\hline Revista de Andalucía & Málaga & $1874-1879$ & $\mathrm{X}$ & \\
\hline Revista de Aragón & Zaragoza & $1900-1905$ & & \\
\hline Revista de España & Madrid & $1868-1894$ & $\mathrm{X}$ & \\
\hline Revista de Geografía Comercial & Madrid & $1885-1896$ & $\mathrm{X}$ & \\
\hline Revista de Navegación y Comercio & Madrid & $1892-1899$ & $\mathrm{X}$ & \\
\hline Revista del Ateneo Escolar de Guadalajara & Guadalajara & $1881-1883$ & & $\mathrm{X}$ \\
\hline Revista Espiritista & Barcelona & $1869-1875$ & $X$ & \\
\hline $\begin{array}{l}\text { Revista Ilustrada de Banca, Ferrocarriles, } \\
\text { Industria y Seguros }\end{array}$ & Madrid & $1896-1936$ & $\mathrm{X}$ & \\
\hline Revista Ilustrada, Vías Férreas & Madrid & $1893-1996$ & $\mathrm{X}$ & \\
\hline Semanario de las Familias & Madrid & $1882-1883$ & $\mathrm{X}$ & \\
\hline Semanario de Palamós & Palamós & $1883-1888$ & & $\mathrm{X}$ \\
\hline Vida Galante & Barcelona & $1898-1905$ & $\mathrm{X}$ & \\
\hline
\end{tabular}

